\title{
A dimensão metafísica da Inteligência Artificial
}

The Metaphysical Dimension of Artificial Intelligence

La dimension métaphysique de l'Intelligence Artificielle

Adriana Andrade Braga e Mônica Chaves

\section{(2) OpenEdition}

\section{Journals}

Edição electrónica

URL: http://journals.openedition.org/rccs/9150

DOI: $10.4000 /$ rccs. 9150

ISSN: 2182-7435

\section{Editora}

Centro de Estudos Sociais da Universidade de Coimbra

\section{Edição impressa}

Data de publição: 1 setembro 2019

Paginação: 99-120

ISSN: 0254-1106

\section{Refêrencia eletrónica}

Adriana Andrade Braga e Mônica Chaves, « A dimensão metafísica da Inteligência Artificial », Revista Crítica de Ciências Sociais [Online], 119 | 2019, posto online no dia 06 agosto 2019, consultado o 14 novembro 2019. URL : http://journals.openedition.org/rccs/9150 


\section{ADRIANA ANDRADE BRAGA, MÔNICA CHAVES}

\section{A dimensão metafísica da Inteligência Artificial}

Este artigo discute o caráter metafísico das narrativas prospectivas acerca da Inteligência Artificial a partir do dualismo cartesiano. Analisamos duas ideias que permeiam o imaginário social em torno das tecnologias digitais a respeito do papel cultural que estas desempenham e de suas consequências na realidade social: a de que, em um futuro breve, numa modernidade utópica (ou distópica), as máquinas se tornarão progressivamente "inteligentes" para o melhoramento (ou dominação) dos seres humanos; e aquela segundo a qual os seres humanos e seus corpos são "máquinas" da natureza e, portanto, passíveis de melhoramento ou transcendência por meio da tecnologia.

Palavras-chave: cartesianismo; desenvolvimento tecnológico; filosofia da tecnologia; inteligência artificial; metafísica.

Só eu posso pensar se Deus existe / só eu / só eu posso chorar quando estou triste / só eu.

GiLberto GIL, Cérebro eletrônico

\section{Introdução}

A criatividade humana aplicada ao desenvolvimento de tecnologias fascina a humanidade desde tempos remotos, ao mesmo tempo em que hipoteticamente traz terríveis ameaças no caso de perda do controle deste processo. Os exemplos são muitos: do Golem mítico da tradição judaica - humano artificial feito de barro e animado por uma palavra sagrada escrita em sua testa - ao monstro do Dr. Frankenstein (1818), do computador Hal, de 2001: A Space Odyssey (1968), aos/às androides rebeldes de Blade Runner (1982) ou o sistema operacional humanizado de Her (2013). ${ }^{1}$ Em todos esses casos, combina-se o encanto com as possibilidades do desenvolvimento

${ }^{1}$ Cf. Shelley, Mary Wollstonecraft (2009), Frankenstein, or The Modern Prometheus. Engage Books, AD Classic [orig. 1818]; Kubrick, Stanley (1968), 2001: A Space Odyssey. Metro-Goldwyn-Meyer; Scott, Ridley (1982), Blade Runner. The Ladd Company, Shaw Brothers e Warner Bros; Jonze, Spike (2013), Her. Annapurna Pictures. 
tecnológico ao terror ante as novas ameaças em que esta mesma técnica se converte.

Este artigo busca discutir o caráter metafísico das narrativas prospectivas acerca da Inteligência Artificial (IA) a partir do dualismo cartesiano corpo-mente. Além disso, identifica duas ideias aparentemente contraditórias que permeiam o imaginário social em torno das tecnologias eletrônico-digitais: a de uma modernidade utópica (ou distópica), em que as máquinas se tornarão cada vez mais "inteligentes" para o melhoramento (ou dominação) dos seres humanos; e aquela segundo a qual os seres humanos e seus corpos seriam "máquinas" da natureza. A matriz filosófica desta concepção dual da "máquina humana" e do "humano maquínico" pode ser traçada desde a filosofia pré-socrática. Entretanto, por meio do nexo cartesiano - o ser humano entendido como a integração entre uma entidade física (o corpo) e uma entidade metafísica distinta (a mente) - fundamenta-se uma forma quase religiosa de representação da ciência, como nas imagens literárias de robôs e computadores dotados de IA.

\section{Dualismo corpo/mente: repensando Descartes}

René Descartes (1596-1650), considerado o pai da filosofia ocidental, deixou um legado importante para o campo científico, principalmente para a filosofia e a matemática. Descartes defendeu filosoficamente a existência de Deus, investigou a relação do humano com a natureza, e desenvolveu o dualismo corpo-mente, com a defesa do livre arbítrio, ponto de partida de nossa reflexão.

O entendimento de que a existência humana se compõe de duas dimensões tem origem na discussão dos filósofos pré-socráticos sobre o princípio da vida, a substância ou força motriz que diferencia os entes animados dos inanimados. Este debate ganha formas mais definidas quando Platão (427-384 a.C.), em Fedro, afirmou a alma como "causa da vida", fazendo, portanto, uma "nítida distinção entre a realidade da alma, simples, incorpórea, que se move por si, que vive e dá vida, e a realidade corpórea, que tem os caracteres opostos" (Abbagnano, 2007: 28). Para ele, corpo e alma têm capacidades e percepções diferentes: no corpo, os sentidos nos permitem apreender o mundo material; na alma, a razão nos possibilita compreender o mundo das ideias. O dualismo corpo-alma, para Platão, é radical, visto que sua concepção de alma é a de algo imortal e indivisível:

A alma aspira a libertar-se do corpo para regressar à sua origem divina e viver, por assim dizer, entre as ideias, no mundo inteligível. Ainda que esteja dentro do corpo, a alma pode recordar as ideias que tinha contemplado puramente em sua vida anterior [no mundo das ideias]. (Ferrater Mora, 1965: 76; tradução das autoras) 
A dimensão divina da alma é repetida por vários pensadores neoplatônicos, de Plotino (204-270 d.C.) a Avicena (980-1037 d.C.), e retomada pela Patrística, notadamente Santo Agostinho (354-430 d.C.), que "recolhe a herança do neoplatonismo e a transmite ao mundo cristão, com o reconhecimento da interioridade espiritual como via de acesso privilegiada à realidade própria da alma" (Abbagnano, 2007: 29). Segundo as determinações agostinianas, corpo e alma não são apenas entes distintos; esta é superior àquele:

[P]orquanto o homem não é apenas alma nem apenas corpo, mas composto de alma e de corpo. É grande verdade não ser todo o homem a alma do homem, mas sua parte superior, nem seu corpo todo o homem, mas sua parte inferior. E também o é que à união simultânea de ambos os elementos se dá o nome de homem, termo que não perde cada um dos elementos, quando deles falamos em separado. (Santo Agostinho, 2001 [426 d.C.]: 124)

No século XVIII, porém, o racionalismo platônico se aprofunda, através do pensamento de Descartes, que explica a relação entre substância pensante (intelectual ou espiritual), chamada res cogitans e a substância extensa (material), chamada res extensa, a partir de argumentos racionais baseados no método da dúvida sistemática (Logan, 2005).

O dualismo cartesiano, portanto, ao mesmo tempo que honra uma tradição filosófica iniciada em Platão, lega para a filosofia moderna uma nova concepção: a de uma alma racional, ou espírito, redefinindo o termo como a substância na qual reside o pensamento. Assim, o uso que Descartes faz da palavra "alma" diferencia-se da acepção que lhe foi dada até então, colocando-a mais próxima do que hoje conhecemos como consciência ou razão. A noção cartesiana de espírito seria adotada, posteriormente, por outros pensadores de abordagem racionalista:

Aqui basta recordar que alguns dos empregos paradoxais às vezes encontrados na filosofia contemporânea se referem na realidade ao significado tradicional instituído por Descartes. Assim, quando L. Klages contrapôs espírito a alma, entendeu por espírito o conjunto das atividades racionais, confrontadas com as tendências instintivas representadas pela alma (Der Geist als Widersacher der Seele, 1929). Por outro lado, G. Santayana entendeu espírito no sentido - também cartesiano - de consciência [...]. De resto, chega a ser supérfluo advertir que, na expressão "ciências do espírito", difundida por Dilthey, entende-se por espírito a atividade racional do homem. (Abbagnano, 2007: 355) 
O dualismo corpo-mente, modelo ainda hoje amplamente adotado em várias áreas de conhecimento, é o pano de fundo das nossas preocupações. Descartes se perguntou como seria possível que o mundo fosse representado pela ciência como algo que obedece a leis definitivas, enquanto o espírito humano escapava das leis da física, uma vez que temos o livre arbítrio. A divisão cartesiana dos seres humanos em duas partes distintas - um corpo sujeito às leis da física e uma mente alheia a elas - legou para a filosofia as considerações centrais da filosofia da mente. A principal questão dessa filosofia é explicar a mente no âmbito da ciência natural, especificamente da física. Este viés cartesiano influenciou vários traços da cultura ocidental e das humanidades. Mais recentemente, essas ideias influenciaram a psicologia e a ciência cognitiva, que tem o dualismo corpo-mente como principal pressuposto.

O desenvolvimento de dispositivos computacionais digitais e eletrônicos renovou o interesse em conciliar os pressupostos filosóficos da mente. O computador é uma máquina que pode reproduzir algumas funções intelectuais humanas, como efetuar cálculos. Essa descoberta inspirou a ideia de que o problema de Descartes poderia ser finalmente resolvido. Com base em uma teoria funcionalista e promovida pelos desenvolvimentos da IA, estudos da filosofia da mente julgaram que, em computadores, o material e o mental funcionam juntos, sem nenhuma substância imaterial, como alma, mente ou um fantasma dentro da máquina. Assim, se pudéssemos entender como um computador pode imitar as funções intelectuais humanas - tomadas como racionais e inteligentes - também poderíamos entender como o funcionamento mecânico do cérebro pode provocar operações mentais. Deste modo, a mente poderia ser entendida em termos de características corporais, e então o problema de conciliar suas propriedades com as leis da física seria resolvido.

A tentativa de entender o funcionamento da mente a partir do funcionamento dos computadores permitiu sugerir que a mente fosse semelhante a um computador que poderia ser descrito como a execução de um software. Essa ideia foi adotada por uma abordagem de psicologia conhecida como "ciência cognitiva". O teste de Turing ${ }^{2}$ fomentou a ideia de que os computadores poderiam ser equivalentes às mentes. A principal premissa do teste é

\footnotetext{
${ }^{2}$ Criado pelo matemático inglês Alan Turing em 1950, este teste visa aferir a capacidade de uma máquina de exibir comportamento semelhante ao de um ser humano. O teste consiste em submeter, de diferentes maneiras, humanos e máquinas a conversas em linguagem natural, por meio de canais de texto, e pedir a um juiz humano que diferencie uns dos outros. Caso o juiz não consiga diferenciá-los, a máquina terá passado no teste. Embora haja controvérsias sobre a validade dos testes baseados no conceito de Turing, este é considerado fundamental para a filosofia da IA.
} 
a de que os computadores serão desenvolvidos até serem capazes de ter os mesmos desempenhos que os humanos. Mas a única maneira de concordar com essa crença é não objetar os princípios desta "possibilidade". No entanto, essa ideia é baseada em um erro sobre a natureza das habilidades humanas.

A mente não é um conceito físico ou biológico, mas isso não significa que seja necessariamente um mistério. Assim, falar em "mente” é também empregar um conceito de senso comum, uma palavra de uso corrente com diversas funções comunicativas, ou seja, uma palavra relacional, e não um fenômeno claramente distinto. Se tudo o que existe fisicamente for pensado apenas na estrutura conceitual da física, química e biologia, ou a mente se torna um enigma metafísico ou deve ser reduzida exclusivamente aos termos dessas ciências (Button et al., 1998).

Nesse sentido, é interessante notar que tenha sido criada uma psicologia científica para explicar o comportamento e a conduta humana como produtos da mente, na qual se sugere que a mente trabalha da mesma forma que um computador, ou seja, que a mente pode ser a causa interna de um comportamento externo - uma perspectiva cartesiana.

Diferentes culturas atribuíram loci distintos para a sede corporal das entidades metafísicas como a alma, a emoção, a inteligência ou a racionalidade. O coração, para os antigos egípcios, era a sede da inteligência (Pinch, 2004); para a medicina de Hipócrates e Galeno, da Antiguidade Clássica ao século XVI, o coração, o fígado e o baço eram sede dos diferentes humores (Bynum, 2011); na cultura ocidental contemporânea, o cérebro é entendido como a sede por excelência da inteligência. A obsessão com a neuroanatomia cerebral levou a situações bizarras "em nome da ciência", como o roubo e a disputa de instituições de pesquisa, museus e universidades pela posse do cérebro de Albert Einstein após sua morte em 1955, comentado por Barthes:

O cérebro de Einstein é um objeto mítico: paradoxalmente a maior inteligência gera a imagem da mecânica mais aperfeiçoada, o homem poderoso demais é separado da psicologia, introduzido num mundo de autômatos. (Barthes, 1989: 60)

Barthes argumenta que, mitologicamente, Einstein é matéria. Seu cérebro, mecânico, sem mistério, órgão superior, fisiológico, "órgão antológico", virou relíquia, peça de museu, legada pelo próprio Einstein ainda em vida. Esta matéria orgânica, cujo poder não se relaciona com o caminho da espiritualidade, conta com uma "moral independente", a "consciência do sábio". Ao registrar ondas de um cérebro ativo, o pensamento é representado como matéria energética, resultado que pode ser medido a partir de um aparato tecnológico que transforma a atividade cerebral em força. 
Tomando Einstein como um produtor de pensamentos, a morte dele teria sido a finalização de uma função específica, como se o cérebro mais potente tivesse parado de pensar.

Através da mitologia de Einstein, o mundo encontrou, deliciado, a imagem de um saber formulado. E - fato paradoxal - quanto mais o gênio do homem se materializava no seu cérebro, tanto mais o produto de sua invenção atingia uma condição mágica, reencarnava a velha imagem esotérica de uma ciência enclausurada em poucas letras. [...] o universo é um cofre cuja combinação o homem procura: Einstein quase a descobriu, eis o mito de Einstein; aí se encontram todos os temas gnósticos: a unidade da natureza, a possibilidade de uma redução fundamental do mundo, o poder de abertura da palavra, a luta ancestral entre um segredo e uma expressão, a ideia de que o saber total pode descobrir-se bruscamente como uma fechadura que cede após mil tentativas infrutuosas. A equação histórica $\mathrm{E}=\mathrm{mc}^{2}$, pela sua simplicidade inesperada, quase concretiza a pura ideia de chave, una, linear, feita de um só metal, abrindo com uma facilidade máxima uma porta contra a qual desde há séculos nos desgastáramos. (Barthes, 1989: 61)

O interesse no estudo neuroanatômico pode ser encontrado já no século XVIII na busca de uma relação da inteligência com a anatomia do cérebro e na tentativa de encontrar o "padrão da inteligência" dos grandes gênios, como no caso do matemático alemão Carl Friedrich Gauss (1777-1855) e do psicólogo russo Ivan Pavlov (1849-1936). Esperava-se encontrar nesta mecânica excepcional a produção de equações complexas. Enquanto a dimensão material da alma permanecer oculta, a ideia de "mente" seguirá sendo operacional para descrever a ação humana.

\section{Narrativas prospectivas acerca da Inteligência Artificial}

O imaginário social é habitado por diferentes versões da ideia de que os seres humanos um dia serão tornados obsoletos pelos computadores. ${ }^{3}$ Defensores destas narrativas prospectivas acerca da IA sugerem que, em um futuro não muito distante - 2045, de acordo com Ray Kurzweil (2011 [2005]) - programadores/as irão projetar um computador com uma capacidade de IA que lhe permitirá se autoaperfeiçoar de modo exponencial. Este supercomputador seria capaz de projetar um computador ainda mais inteligente do que ele, que seria capaz por sua vez de fazer o mesmo e, por um processo de iteração, em algum momento, um ponto de singularidade tecnológica seria alcançado, ou seja, a possibilidade de existirem computadores e robôs singulares com

\footnotetext{
${ }_{3}$ Uma versão preliminar desta reflexão pode ser encontrada em Braga e Logan (2017).
} 
capacidade de aprender com os próprios erros e assim desenvolver empatia, objetivos, capacidade de decisão e improviso, por exemplo. De acordo com esta narrativa, os computadores pós-singularidade seriam muito mais inteligentes do que os humanos, que só possuem uma inteligência projetada pela natureza através de evolução e seleção natural. Assim, entre os/as que defendem essa ideia, há os/as que acreditam que a singularidade levará a humanidade a encontrar soluções para problemas milenares, e outros/as que temem que estes computadores superinteligentes assumam o controle, reduzindo os seres humanos a dóceis servos.

Para fundamentar nossa crítica à ideia de que a IA levará inevitavelmente à singularidade tecnológica, é preciso inicialmente situar o conceito de IA como uma disciplina atravessada pelos conhecimentos das áreas da "cognição, das neurociências e da informática, buscando compreender o pensamento e o comportamento humanos, a fim de reproduzi-los artificialmente" (Pessis-Pasternak, 1992: 193-194). Em uma definição mais contemporânea, Wang, Liu e Dougherty afirmam que "em seu sentido mais amplo, a Inteligência Artificial (IA) é a tentativa de 'fazer um computador semelhante à mente humana'” (Wang et al., 2018: 2; tradução das autoras).

Já a ideia de singularidade, que tem como porta-voz o futurista norte-americano Ray Kurzweil, baseia-se na suposição de que a "inteligência não biológica" irá superar a inteligência humana quando "nanorrobôs inteligentes" estiverem integrados aos corpos e cérebros humanos, uma visão dualista. Ao prever que a inteligência não biológica "será capaz de se aprimorar, em um ciclo de redesign incrivelmente rápido”, Kurzweil (2011 [2005]; tradução das autoras) refere-se à chamada strong AI. Para ele, isso significa que "tanto o hardware quanto o software recriarão a inteligência humana até o fim dos anos 2020" (ibidem). ${ }^{4}$ Ao indicar as duas dimensões em que a inteligência será recriada, o autor nos sugere uma analogia entre o dualismo corpo-mente de Descartes e um novo dualismo hardware-software, em que a materialidade do corpo seria equiparável à existência física do hardware, e, portanto, a transcendência da mente poderia ser substituída pela imaterialidade do software, até que, em 2030, a parte não biológica da inteligência humana iria predominar:

\footnotetext{
${ }^{4}$ No original, o trecho na íntegra: "The robotics revolution, which really refers to 'strong' AI, that is, artificial intelligence at the human level, which we talked about earlier. We'll have both the hardware and software to recreate human intelligence by the end of the 2020s. We'll be able to improve these methods and harness the speed, memory capabilities, and knowledge-sharing ability of machines".
} 
Por fim, nós seremos capazes de escanear todos os detalhes importantes dos nossos cérebros por dentro deles, usando bilhões de nanorrobôs nos capilares. Poderemos, então, fazer backups de informações. Usando produtos feitos com nanotecnologia, poderíamos recriar nossos cérebros, ou, melhor ainda, reinstanciá-los em um substrato computacional mais capaz. (Kurzweil, 2011 [2005]; tradução das autoras)

Esta visão da mente humana como algo que pode ser mapeado e, portanto, replicado, já era antecipada por Edward Feigenbaum, que considerava sistemas especializados como sendo um primeiro passo em direção à criação de um computador dotado de inteligência semelhante à humana, pois, para ele,

nosso cérebro não passa de uma potente máquina de tratamento de informações. É por isso que, quando formos capazes de analisar meticulosamente o funcionamento deste, seremos capazes também de criar um programa equivalente de tratamento dos símbolos pelo computador. (Feigenbaum in Pessis-Pasternak, 1992: 217).

Retomando a definição proposta por Wang, Liu e Dougherty, há três significados possíveis para a IA:

um sistema de computador que se comporta exatamente como a mente humana; um sistema de computador que resolve certos problemas anteriormente solucionáveis apenas pela mente humana; ou um sistema de computador com as mesmas funções cognitivas que a mente humana (Wang et al., 2018: 2; tradução das autoras).

$\mathrm{Na}$ visão dos autores, esta primeira definição de IA baseia-se em uma interpretação antropocêntrica de "inteligência", que, portanto, deveria ser chamada de Inteligência Humana Artificial: "definir a inteligência em geral a partir do comportamento humano tornaria outras formas de inteligência ('inteligência animal', 'inteligência coletiva', 'inteligência extraterrestre', etc.) impossíveis por definição" (ibidem: 3 ). Assim, a ideia de que a IA seria similar à mente humana parte de uma premissa equivocada, uma vez que, se um computador "não é um organismo biológico, nem vive uma vida humana, não se pode esperar que ele seja similar à mente humana em todos os seus detalhes" (ibidem: 2; tradução das autoras). Por outro lado, as pesquisas destes autores sobre Artificial General Intelligence (AGI, Inteligência Geral Artificial) têm outras premissas e objetivos:

A AGI deve ser pensada como um sistema de computador que é similar à inteligência humana em seus princípios, mecanismos e funções, mas não necessariamente em sua 
estrutura interna, comportamentos externos e capacidade de resolução de problemas. Consequentemente, por ser uma outra forma de inteligência, a AGI dificilmente estaria no mesmo nível de competência da inteligência humana, nem maior, nem menor. No caso da sua capacidade de resolução de problemas concretos, a AGI nem sempre é comparável à inteligência humana, pois elas podem estar lidando com problemas diferentes, em ambientes diferentes. (Wang et al., 2018: 13; tradução das autoras)

Os autores ainda questionam a própria crença de que a inteligência artificial levará à singularidade tecnológica, entre outros motivos, por entenderem que essa ideia se baseia na falsa premissa de que a inteligência pode ser medida por um número real, e por reconhecerem que a capacidade de aprendizagem exponencial de um sistema tem características apenas funcionais, não similares às humanas. $\mathrm{O}$ sistema desenvolvido por suas equipes, nesse sentido, recebeu o nome de Non-Axiomatic Reasoning System (NARS, Sistema de Raciocínio Não-Axiomático), desvinculando as capacidades do sistema de uma tentativa de replicar a chamada "inteligência". O NARS é um sistema de AGI capaz de ter "experiências", (moldado pela experiência do sistema), de fazer "julgamentos" (apenas entre um suposto "bem" e "mal"), de adquirir "sabedoria" (programas pré-elaborados que guiam o sistema para atingir certos objetivos) e de desenvolver "intuição" (crenças cuja origem é vaga). Porém, os pesquisadores ressaltam que essas características estão sendo entendidas em seus aspectos funcionais, e não nos biológicos:

Uma refutação previsível às nossas conclusões acima é considerar que as versões do NARS para essas características são "falsas", já que uma ou outra não são idênticas às versões humanas. Mais uma vez, [essa objeção] remonta ao entendimento de "IA" e do quão próximo este deveria ser da inteligência humana. Tomemos as emoções como um exemplo: mesmo quando totalmente desenvolvidas, as emoções do NARS não serão idênticas às emoções humanas, nem estarão acompanhadas dos processos psicológicos que são ingredientes intrínsecos das emoções humanas. No entanto, essas diferenças não podem ser usadas para considerar como falsas as emoções da AGI, enquanto [o conceito de] "emoção" estiver sendo usado como generalização de "emoção humana", mantendo seus aspectos funcionais, mas não os biológicos. (Wang et al., 2018: 13; tradução das autoras)

Essa perspectiva não antropocêntrica da IA também norteou o pensamento de Heinz von Foerster, que já em 1984 afirmava não ser possível imitar os processos do pensamento humano, pois não saberíamos sequer 
o que imitar, dado que não conhecemos seu modo de funcionamento em todos os aspectos. Para o autor:

Infelizmente, constata-se com bastante frequência, na Ciência Informática, uma atitude antropomórfica, que consiste em observar o que fazem certas máquinas e atribui-se-lhes uma terminologia humana. Por exemplo, a perpétua referência à "memória": mas os computadores não têm memória! Nunca teremos uma máquina capaz de escrever suas Memórias! Os computadores têm sim elementos de armazenagem que lhes permitem conservar números ou programas. Existe uma enorme diferença entre uma "memória" e um "sistema de armazenamento": este último só pode reproduzir o que foi nele colocado, ao passo que a memória é um processo de transformação. (von Foerster in Pessis-Pasternak, 1992: 202)

Diante dessas perspectivas distintas sobre qual é a lógica que rege o desafio de desenvolver formas artificiais de interpretar e reagir a situações externas, podemos perceber que mesmo na investigação das áreas de tecnologia e ciências da informação não há consenso sobre as premissas, os objetivos ou os resultados esperados destes sistemas.

É importante notar que a popularização da ideia da singularidade num futuro próximo é produto de tecno-otimistas e do mundo dos negócios, que fizeram outras previsões no passado que não se cumpriram. Uma delas, por exemplo, foi a de que com a eficiência dos computadores haveria uma diminuição drástica no número de horas de trabalho, previsão que ainda não se concretizou (Novak, 2014). "Por exemplo, as estações de trabalho com computador revolucionaram o escritório e o varejo [...] No entanto, o aumento drástico da produtividade não levou a uma semana de trabalho mais curta ou a um ambiente de trabalho mais flexível" (Gibson, 2007: 74; tradução das autoras). Em vez disso, as empresas passaram a usar a eficiência dos computadores para reduzir o número de trabalhadores/as necessários/as para executar certas tarefas. Ao longo dos últimos 30 anos, muitos proclamaram a chegada iminente do escritório sem papel e do "capitalismo sem atritos" (e. g. Gates, 1995). No entanto, mesmo a World Wide Web, que permite que praticamente qualquer computador leia e exiba os documentos de outro computador, aumentou de forma significativa a quantidade de impressões feitas. Segundo Sellen e Harper (2003: 1), o uso de e-mail em uma organização causa um aumento médio de $40 \%$ no consumo de papel.

Algumas das narrativas prospectivas sobre a singularidade parecem ter um zelo "religioso" com a questão, não no sentido teológico, mas um pouco 
semelhante aos deístas, em busca de uma dimensão metafísica da tecnologia: o transumanismo.

A tentativa de lidar com as vicissitudes da vida e da morte por meio de tecnologias não é novidade. No clássico $O$ mal-estar na civilização, Freud (1974 [1929]: 106) afirma que todas as coisas que fazemos para nos proteger contra ameaças e sofrimento fazem parte da civilização. O sofrimento é tratado por Freud como uma ameaça que se apresenta em algumas direções: de nosso próprio corpo, condenado à inevitável decrepitude; do mundo externo, que pode ser hostil com forças cruéis e destruidoras; e de nossos relacionamentos com outros humanos. A única forma de defesa contra o sofrimento vindo do temível mundo externo é tentar afastar-se dele. Entretanto,

há outro caminho, e melhor: o de tornar-se membro da comunidade humana e, com o auxílio de uma técnica orientada pela ciência, passar para o ataque à natureza e sujeitá-la à vontade humana. Trabalha-se então com todos para o bem de todos. (Freud, 1974 [1929]: 96)

A vertente metafísica da tecnologia chamada transumanismo oferece algumas opções contra a decadência do corpo, como o humano maquínico; ou contra as ameaças do mundo externo, como a IA (a máquina inteligente). Assim, oferece por meio do cientificismo uma proposta de transcendência espiritual tecnologicamente mediada que, no seu extremo, limitaria o escopo da ação humana. Nesse sentido, Hofkirchner ressalta que

O bomo sapiens é, em princípio, propenso a erros, enquanto um mecanismo (máquina) é passível de falha apenas no caso de erros do operador, erros de programação ou defeitos do material, todos podendo ser considerados como "falha humana". Uma abordagem dualista tecnogênica pode então advogar "sistemas autônomos" que funcionam automaticamente e sem interferência humana, se programam a si mesmos e constroem, consertam, reparam e se reciclam a si mesmos. O conceito resultante de autonomia é aquele em que um mecanismo é modelado como algo completamente diferente do homem/sociedade. A autonomia, anteriormente reservada para a designação da liberdade humana, torna-se uma propriedade pretendida dos artefatos. Essa autonomia, além disso, acabaria por limitar a liberdade humana e a autonomia humana. (Hofkirchner, 2018: 12; tradução das autoras)

A seguir, destacamos algumas das narrativas justificativas do transumanismo, tendo em vista sua descrição tanto da a) máquina humanizada quanto do b) humano maquínico. 


\section{a) Metafísica da máquina humanizada}

Nas narrativas sobre a relação entre humanos e tecnologias computacionais são usadas várias metáforas que tratam os computadores como humanos e vice-versa. A respeito destas abordagens, Neil Postman aponta significados que não podem ser considerados inocentes, derivados do que chama de "tecnopólio", um regime em que a tecnologia se sobrepõe à vida cultural e para o qual algumas sociedades já estariam hoje caminhando. A criação do computador trouxe consigo uma redefinição de humanos enquanto "processadores de informação" e da natureza enquanto "informação a ser processada". Assim, "a mensagem metafórica fundamental do computador é que nós somos máquinas - máquinas pensantes, é bem verdade, mas ainda assim máquinas" (Postman, 1992: 117).

Esses limites flexíveis, ao nível do discurso, entre o conceito de humanidade e o mundo das máquinas são, como alerta Postman, uma alegoria irrefletida:

Em outras palavras, o que temos aqui é uma metáfora que endoidou. A partir da proposição de que os humanos são em certos aspectos como as máquinas, passamos para a proposição de que os humanos são pouco mais que máquinas e, por fim, que os humanos são máquinas. E depois, como seria inevitável, pelo que sugere a observação de [John] McCarthy ${ }^{[5]}$ passamos para a proposição de que as máquinas são seres humanos. (ibidem: 118)

Postman esclarece a impropriedade de se considerar os experimentos da área da chamada IA como tentativas de replicar ou mesmo transpor a mente humana nas máquinas, ao analisar o modo como os/as criadores/as do software ELIZA ${ }^{6}$ definiram as tarefas que o sistema poderia executar:

Máquinas não podem sentir e, tão importante quanto, não podem compreender. ELIZA pode perguntar: "Por que você está preocupado com sua mãe?", que podia ser exatamente a pergunta que um terapeuta faria. Mas a máquina não sabe o que a pergunta significa, ou mesmo que a pergunta significa algo. (ibidem)

Experimentos destinados a criar máquinas capazes de emular interações humanas não são novidade; Alan Turing testou essa possibilidade desde

\footnotetext{
${ }^{5}$ A John McCarthy é atribuída a autoria do termo Inteligência Artificial.

${ }^{6}$ Segundo Neil Postman, ELIZA é um software desenvolvido por Joseph Weizenbaum, no Laboratório de Inteligência Artificial do Massachussets Institute of Technology, que é capaz de elaborar perguntas sobre palavras-chave apresentadas à máquina, inverter declarações e pedir mais informações sobre um dos substantivos da frase.
} 
os anos 1930. Já os desdobramentos de sua pesquisa levaram ao que Hayles chama de pós-humanismo:

Enquanto o teste de Turing foi projetado para mostrar que as máquinas podem executar pensamentos, o que até então era considerado uma capacidade exclusiva da mente humana, o teste de [Hans] Moravec foi projetado para mostrar que as máquinas podem se tornar repositórios da consciência humana - que as máquinas podem, para todos os efeitos, se tornar seres humanos. (Hayles, 1999: xi-xii; tradução das autoras)

As consequências desta visão do pós-humanismo são analisadas por Hayles, que as desdobra em quatro pontos:

a) Passa-se a privilegiar o padrão informacional em detrimento da representação material. Assim, "a corporificação em um substrato biológico é vista como um acidente da história em vez de uma inevitabilidade da vida" (1999: 2; tradução das autoras).

b) A consciência, que há séculos vem sendo considerada pela cultura ocidental como o lugar da identidade humana, passa a ser considerada "um epifenômeno, como se fosse uma arrivista evolucionária alegando ser todo o espetáculo, quando na verdade seria apenas uma parte menor do show" (ibidem: 3 ).

c) O corpo passa a ser entendido como "a prótese original que todos nós aprendemos a manipular, de modo que estendê-lo ou substituí-lo por outras próteses torna-se uma continuação de um processo que se iniciou antes de termos nascido" (ibidem).

d) Configura-se o ser humano como se ele pudesse "ser perfeitamente articulado a máquinas inteligentes" (ibidem).

Diante deste quadro, Hayles concluiu que no pós-humanismo "não há diferenças essenciais ou demarcações absolutas entre a existência corpórea e a simulação computacional, mecanismo cibernético e organismo biológico, teleologia robótica e objetivos humanos" (ibidem). ${ }^{7}$

\footnotetext{
${ }^{7}$ No original, o trecho na íntegra: "First, the posthuman view privileges informational pattern over material instantiation, so that embodiment in a biological substrate is seen as an accident of history rather than an inevitability of life. Second, the posthuman view considers consciousness, regarded as the seat of human identity in the Western tradition long before Descartes thought he was a mind thinking, as an epiphenomenon, as an evolutionary upstart trying to claim that it is the whole show when in actuality it is only a minor sideshow. Third, the potshuman view thinks of the body as the original prosthesis we all learn to manipulate, so that extending or replacing the body with other prostheses becomes a continuation of a process that began before we were born. Fourth, and most important, by these and other means, the posthuman view configures human being so that it can be seamlessly articulated with intelligent machines. In the postuhuman, there are no essential differences or absolute demarcations between bodily existence and computer simulation, cybernetic mechanism and biological organism, robot teleology and human goals".
} 
Uma série de autores exploram estas visadas prospectivas sobre o futuro da IA. Em um texto intitulado "I, for One, Welcome Our Machine Overlords", Anthony Garrett Lisi afirmou: "Os computadores compartilham o conhecimento muito mais facilmente do que os humanos e mantêm esse conhecimento por mais tempo, tornando-se mais sábios do que os humanos" (2015: 22; tradução das autoras). Lisi, em sua tentativa de encontrar um poder superior, toma como dado adquirido que a sabedoria vem do conhecimento. No entanto, entendemos que o conhecimento se relaciona com o uso de informações na busca de objetivos, pelo que sabedoria, nesse sentido, seria a capacidade de escolher objetivos consistentes com os próprios valores. Ora, como um computador pode ter valores? Os valores vêm de seus/suas programadores/as.

Sam Harris sugeriu que uma IA forte poderia atingir 20 mil anos de trabalho intelectual em uma semana. O trabalho científico requer fazer observação, projetar e construir ferramentas de observação. Seus comentários finais revelam o que identificámos como um fervor quase religioso da defesa da AGI: "Parece que estamos no processo de construir um Deus. Agora seria um bom momento para se perguntar se Ele será (ou até se pode ser) um Deus bom” (Harris, 2015: 411; tradução das autoras).

James Croak defendeu que: "O medo da IA é a última encarnação do nosso medo primal inconsciente de um Deus raivoso onisciente e todo-poderoso que nos domina, mas de uma nova forma etérea" (Croak, 2015: 498; tradução das autoras).

Um cenário apocalíptico do impacto da singularidade é apresentado por Douglas Hofstadter (2008), que acredita estar a um "par de séculos" de distância. Este autor sugere que as ramificações

serão imensas, na medida que a forma mais alta de seres conscientes no planeta não será mais humana. Talvez essas máquinas - nossos "filhos" - serão vagamente como nós e terão uma cultura semelhante à nossa, mas provavelmente não. Nesse caso, nós, seres humanos, podemos muito bem seguir o caminho dos dinossauros [a extinção]. (ibidem; tradução das autoras)

Parece um mistério pensar o que faz um/a cientista acreditar que a inteligência humana pode ser programada ou criada em um computador, uma máquina mecânica. No pequeno ensaio "Thinking Does Not Imply Subjugating”, Steven Pinker (2015) descreveu sucintamente a sua crença de que as inteligências humanas poderiam ser capturadas em uma máquina: 
Os feitos cognitivos do cérebro podem ser explicados em termos físicos [...] Esta é uma ideia atraente por dois motivos. Primeiro, completa uma compreensão naturalista do universo, exorcizando almas ocultas, espíritos e fantasmas na máquina. Assim como Darwin tornou possível para um observador pensativo apreender o mundo natural sem o criacionismo, Turing e outros tornaram possível que um observador pensativo pudesse apreender o mundo cognitivo sem o espiritualismo. (Pinker, 2015: 5; tradução das autoras)

As posições apresentadas apontam para uma linha de pensamento que entende os seres humanos e as máquinas não apenas como entes de categorias ontologicamente equivalentes, mas também quase como oponentes em uma guerra pela sobrevivência. A este raciocínio, que se alinha com o que Simondon (2008 [1958]) chama de "tecnicismo intemperante", corresponderia uma "idolatria da máquina", fruto da atribuição de um caráter sagrado aos objetos técnicos e de uma "aspiração tecnocrata ao poder incondicional". Assim,

o desejo de poder consagra a máquina como meio de supremacia e faz dela o elixir moderno. $\mathrm{O}$ homem que quer dominar seus semelhantes suscita a máquina andróide. Diante dela, ele abdica de sua humanidade e a delega. Ele busca construir a máquina de pensar, sonhando poder construir a máquina de querer, a máquina de viver, para ficar atrás dela sem angústia, liberado de todo perigo, eximido de todo sentimento de fraqueza e triunfante mediante sua invenção. (Simondon, 2008 [1958])

\section{b) Metafísica do humano maquínico}

Paralelamente à metafísica da máquina humanizada, existem narrativas do humano maquínico, segundo as quais o avanço tecnológico se dará para dentro do corpo humano, de modo que um "upload humano" - integração plena da mente em um contexto maquínico - seria o ponto de passagem de uma dimensão a outra.

Uma solução para a questão metafísica da vida após a morte foi apresentada por Frank Tipler (2015) para o fato inevitável de que quando o Sol se esgotar - como combustível nuclear e já não possa fornecer as condições que tornam a vida na Terra sustentável -, a única esperança para a sobrevivência da cultura humana será através dos computadores de IA, uma vez que não requerem condições que tornem sustentável a vida. E assim,

Qualquer humano que se queira juntar à IA em sua expansão pode se tornar um upload humano, uma tecnologia que deve ser desenvolvida ao mesmo tempo que a tecnologia da IA [...] Se você não os pode vencer, junte-se a eles [...] Quando esta 
desgraça acontecer, qualquer humano que permaneça vivo e que não queira morrer não terá escolha senão tornar-se um upload humano. [...] A IA nos salvará a todos. (Tipler, 2015: 18; tradução das autoras)

A aproximação de Tipler com o cristianismo é notável. A IA "nasceu" para ser o "Salvador" da humanidade. Assim, ironicamente, a vida eterna poderia ser encontrada em um computador com IA em qualquer lugar no espaço, do mesmo modo que a vida eterna está no "reino dos céus".

Pamela McCorduck, em um artigo intitulado "An Epocal Human Event", afirmou:

Nós desejamos nos salvar e nos preservar enquanto espécie. Para todas as divindades imaginárias que invocamos ao longo da história e que não conseguiram nos salvar e proteger - da natureza, uns dos outros, de nós mesmos - estamos finalmente prontos para chamar, em substituição, as nossas próprias mentes aprimoradas e aumentadas. (McCorduk, 2015: 53; tradução das autoras)

É interessante notar que a entidade divina evocada aqui são as "nossas próprias mentes aprimoradas e aumentadas", ou seja, computadores dotados de IA forte. Por fim, apresenta-se um deboche da crença na vida eterna da autoria de John Horgan (2008), cético relativamente à ideia de singularidade:

Eu adoraria acreditar que estamos nos aproximando rapidamente da "singularidade". Como o paraíso, a singularidade tecnológica vem em muitas versões, mas a maioria envolve o aprimoramento do cérebro biônico. Em primeiro lugar, nos tornaremos cyborgs, porque chips cerebrais incrivelmente poderosos vão alterar a nossa percepção, memória e inteligência e talvez até eliminar a necessidade de controles de TV irritantes. Eventualmente, abandonaremos completamente nossos seres de carne e osso e carregaremos nossas psiques digitalizadas em computadores. Vamos então morar felizes para sempre no ciberespaço [...] (Horgan, 2008; tradução das autoras)

Horgan permanece cético quanto aos uploads de cérebros humanos para os computadores principalmente porque os neurocientistas têm uma compreensão apenas esboçada de como o cérebro opera, de como armazena memórias e sobre os papéis dos vários químicos encontrados nele (Horgan, 2008).

Toda definição de inteligência é uma tentativa de organizar um conjunto complexo de fenômenos. Muitas destas definições são resultado da criação e aplicação de testes psicométricos que mensuram diversos fatores, que são entendidos - não de modo absoluto - como habilidades cognitivas, 
reconhecidas pelo termo "inteligência". O senso comum acerca da inteligência está relacionado, muitas vezes, com a performance escolar e com as habilidades sociais. De qualquer forma, o reconhecimento público da posse de uma inteligência privilegiada é a afirmação de um valor social incontestável.

\section{Considerações finais}

Historicamente, o mercado, a indústria e a publicidade têm usado a ideia de "inteligência" para valorizar suas ações e produtos. A ideia da "Inteligência Artificial", assim, se apresenta como um ativo com alto potencial de mercado, que movimenta pesquisas, indústrias e economias vultosas. Segundo dados divulgados na revista Forbes (Press, 2016), estima-se para a pesquisa em Inteligência Artificial um mercado de 1,2 trilhões de dólares em 2020. Esta força econômica ao serviço de uma ideia produz uma série de efeitos na cultura e no imaginário sociais, como o surpreendente retorno à metafísica e à transcendência por meio da tecnologia, presente na ideia de transumanismo.

Neste trabalho, foram identificadas duas ideias distintas que permeiam o imaginário social sobre as tecnologias digitais a respeito do papel cultural que estas desempenham e de suas consequências na realidade social: a de que, em um futuro breve, as máquinas desenvolverão autoconsciência; e a de que os seres humanos e os seus corpos são como máquinas da natureza e, portanto, passíveis de melhoramento ou transcendência por meio da tecnologia.

A respeito destas duas proposições - que a princípio pareceriam pertencer a campos ideológicos opostos -, a teoria do tecnopólio de Postman demonstra que elas são complementares, dado que o raciocínio que entende o corpo humano como uma máquina é também a lógica subjacente às fantasias futuristas de sociedades controladas por máquinas.

Se por um lado a existência humana é obviamente possível sem a presença de dispositivos digitais, por outro, as máquinas enquanto criações humanas que são, só podem existir em um mundo dominado pelos seres humanos. Sendo assim, podemos questionar as narrativas acerca do futuro da IA que aceitam, sem muita contenda, a possibilidade de existência de máquinas autoconscientes ou de transposições da mente humana para outros suportes materiais, pensamento sintetizado por Hayles da seguinte forma: "a crença de que a informação pode circular, sem se modificar, por meio de diferentes substratos materiais" (1999: 1; tradução das autoras).

Ao explorarmos a dimensão metafísica das narrativas acerca do futuro da IA, parece acertada a observação pessimista de James Carey (1992), 
para quem intelectuais e cientistas, justamente aqueles/as que possuiriam mais recursos para entender o rumo da história, muitas vezes acabam se transformando em evangelistas da "psicose técnica" ao invés de entenderem que não estão nas novas tecnologias as soluções "para o que são, na verdade, problemas políticos duradouros" (ibidem: 137; tradução das autoras).

A agência humana está em posição de manifestar qualidades que os computadores ainda não podem e talvez nunca sejam capazes de ter (Braga e Logan, 2017): propósitos, objetivos, metas, telos e cuidados, intuição, imaginação, humor, emoções, curiosidade, criatividade e estética, valores e moralidade. Todas essas características constituem um senso de identidade que se desenvolveu durante milhões de anos de evolução natural e social.

A racionalidade ocidental nunca foi ingênua. Seu projeto estabelece-se na história como projeto de poder. [...] O corpo tornou-se menos físico e mais simbólico, e com ele apaga-se a matéria e a vida concreta, em nome de verdades 'transcendentais' e, em última instância, 'racionais'. A racionalidade esgota seu alcance quando vai mais longe do que as próprias pessoas que poderiam servir-se dela. (Tiburi, 2016: 13)

\section{Referências bibliográficas}

Abbagnano, Nicola (2007), Dicionário de filosofia. São Paulo: Martins Fontes. Tradução de Alfredo Bosi e Ivone Castilho Benedetti [orig. 1971].

Barthes, Roland (1989), "O cérebro de Einstein", in Mitologias. Rio de Janeiro: Bertrand Brasil, 60-62. Tradução de Rita Buongermino e Pedro de Souza [orig. 1957].

Braga, Adriana; Logan, Robert K. (2017), "The Emperor of Strong AI Has No Clothes: Limits to Artificial Intelligence”, Information, 8(4). Consultado a 28.06.2019, em https://www.mdpi.com/2078-2489/8/4/156/htm.

Button, Graham; Coulter, Jeff; Lee, John; Sharrock, Wes (1998), Computadores, mentes e conduta. São Paulo: Editora UNESP. Tradução de Roberto Leal Ferreira.

Bynum, William (2011), História da Medicina. Porto Alegre: L\&PM Pocket. Tradução de Flávia Souto Maior.

Carey, James (1992), Communication as Culture: Essays on Media and Society. New York: Routledge.

Croak, James (2015), "Fear of a God, Redux", in John Brockman (org.), What to Think about Machines that Think. New York: Harper Perennial, 498-499.

Ferrater Mora, José (1965), Diccionario de filosofia, 2 volumes. Buenos Aires: Sudamericana. Freud, Sigmund (1974), "O mal-estar na civilização", in Obras psicológicas completas de Sigmund Freud, vol. XXI. Rio de Janeiro: Imago, 75-174. Tradução de José Octávio de Aguiar Abreu [orig. 1929]. 
Gibson, Kevin (2007), Ethics and Business: An Introduction. Cambridge: Cambridge University Press.

Harris, Sam (2015), "Can We Avoid a Digital Apocalypse?”, in John Brockman (org.), What to Think about Machines that Think. New York: Harper Perennial, 408-411.

Hayles, Katherine (1999), How We Became Postbuman? Virtual Bodies in Cybernetics, Literature, and Informatics. Chicago: The University of Chicago Press.

Hofkirchner, Wolfgang (2018), Promethean Shame Revisited: A Praxio-Onto-Epistemological Analysis of Cyber Futures. Singapore: World Scientific.

Hofstadter, Douglas (2008), “Tech Luminaries Address Singularity”, IEEE Spectrum, 1 de junho. Consultado a 28.06.2019, em http://spectrum.ieee.org/computing/ hardware/tech-luminaries-address-singularity.

Horgan, John (2008), “The Consciousness Conundrum”, IEEE Spectrum, 1 de junho. Consultado a 28.06.2019, em http://spectrum.ieee.org/biomedical/imaging/theconsciousness-conundrum.

Kurzweil, Ray (2011), "Singularity Q\&A", Kurzweil Network-Accelerating Intelligence, 9 de dezembro [orig. 2005]. Consultado a 26.07.2018, em http://www.kurzweilai. net/singularity-q-a.

Lisi, Anthony Garrett (2015), "I, for One, Welcome Our Machine Overlords”, in John Brockman (org.), What to Think about Macbines that Think. New York: Harper Perennial, 22-24.

Logan, Robert K. (2005), "The Origin and Evolution of Language and the Transformation of Meaning, Identity and Relationships in CMC", in Adriana Braga (org.), CMC, identidades e género: teoria e método. Covilhã: UBI, 235-262.

McCorduck, Pamela (2015), "An Epochal Human Event”, in John Brockman (org.), What to Think about Machines that Think. New York: Harper Perennial, 51-53.

Novak, Matt (2014), “The Late Great American Promise of Less Work”, Paleofuture, 4 de outubro. Consultado a 28.06.2019, em http://paleofuture.gizmodo.com/ The-late-great-american-promise-of-less-work-1561753129.

Pessis-Pasternak, Guitta (1992), Do caos à inteligência artificial: quando os cientistas se interrogam. Entrevistas de Guitta Pessis-Pasternak. São Paulo: Editora UNESP. Tradução de Luiz Paulo Rouanet [2. ${ }^{a}$ ed.].

Pinch, Geraldine (2004), Egyptian Mythology: A Guide to the Gods, Goddesses, and Traditions of Ancient Egypt. Oxford: Oxford University Press.

Pinker, Steven (2015), "Thinking Does Not Imply Subjugating”, in John Brockman (org.), What to Think about Machines that Think. New York: Harper Perennial, 5-8.

Postman, Neil (1992), Tecnopólio: a rendição da cultura à tecnologia. São Paulo: Studio Nobel. Tradução de Reinaldo Guarany. 
Press, Gil (2016) "Forrester Predicts Investment in Artificial Intelligence Will Grow $300 \%$ in 2017", Forbes, 1 de novembro. Consultado a 28.06.2019, em https://www. forbes.com/sites/gilpress/2016/11/01/forrester-predicts-investment-in-artificialintelligence-will-grow-300-in-2017/\#29c61a585509.

Santo Agostinho, (2001), A cidade de Deus (contra os pagãos). Parte II. Petrópolis: Editora Vozes. Tradução de Oscar Paes Leme [4. ${ }^{\text {a }}$ ed.; orig. 426 d.C.].

Sellen, Abigail; Harper, Richard (2003), The Myth of the Paperless Office. Cambridge, MA: MIT Press.

Simondon, Gilbert (2008), Du mode d'existence des objets techniques. Paris: Aubier-Montaigne. Tradução de Pedro Peixoto Ferreira e revisão de Christian Pierre Kasper [orig. 1958]. Consultado a 28.07.2017, em https://cteme.wordpress.com/ publicacoes/do-modo-de-existencia-dos-objetos-tecnicos-simondon-1958/.

Tiburi, Marcia (2016), "Prótese da Fé”, Revista Cult, 213, p. 13.

Tipler, Frank (2015), “If You Can't Beat 'Em, Join 'Em”, in John Brockman (org.), What to Think about Machines that Think. New York: Harper Perennial, 17-18.

Wang, Pei; Liu, Kai; Dougherty, Quinn (2018), “Conceptions of Artificial Intelligence and Singularity”, Information, 9(4). Consultado a 26.07.2018, em http://www.mdpi. com/2078-2489/9/4/79/htm.

Artigo recebido a 23.07.2017

Aprovado para publicação a 10.01.2019

\section{Adriana Andrade Braga}

Departamento de Comunicação, Pontifícia Universidade Católica do Rio de Janeiro

Rua Marquês de São Vicente, 225, Prédio Kennedy, 6. ${ }^{\circ}$ andar,

CEP: 22451-900, Gávea, Rio de Janeiro, Brasil

Contacto: adrianabraga@puc-rio.br

ORCID: https://orcid.org/0000-0002-0307-3470

\section{Mônica Chaves}

Mestranda no Programa de Pós-Graduação em Comunicação Social, Departamento de Comunicação, Pontifícia Universidade Católica do Rio de Janeiro

Rua Marquês de São Vicente, 225, Prédio Kennedy, 6. ${ }^{\circ}$ andar,

CEP: 22451-900, Gávea, Rio de Janeiro, Brasil

Contacto: contato@monicachaves.jor.br

ORCID: https://orcid.org/0000-0002-9424-8036 


\section{The Metaphysical Dimension of Artificial Intelligence}

This article discusses - by way of Cartesian dualism - the metaphysical aspects of prospective narratives regarding Artificial Intelligence. Two ideas permeate the social imaginary regarding digital technologies and the role they play in culture and their consequences in the social world: the first notion is one where, in the near future of utopic (or dystopic) modernity, machines will become progressively "intelligent" for the betterment (or domination) of human beings. According to the second, human bodies are natural "machines", and thus capable of improvement or transcendence by means of technology.

Keywords: Artificial Intelligence; Cartesianism; metaphysics; philosophy of technology; technological development.

\section{La dimension métaphysique de l'Intelligence Artificielle}

Cet article se penche sur le caractère métaphysique des narratives prospectives à propos de l'Intelligence Artificielle à partir du dualisme cartésien. Deux idées prévalent sur l'imaginaire social à propos des technologies numériques quant au rôle culturel qu'elles jouent et quant à leurs conséquences sur la réalité sociale: celle, dans un avenir proche, d'une modernité utopique (ou dystopique), selon laquelle les machines deviendront progressivement "intelligentes" pour améliorer (ou dominer) le genre humain; et celle d'après laquelle les êtres humains et leurs corps sont des "machines" de la nature et, donc, passibles d'amélioration ou de transcendance par le biais de la technologie. Mots-clés: cartésianisme; développement technologique; intelligence artificielle; métaphysique; philosophie de la technologie. 
